\title{
The Study of the Difficulty in Starting a Diesel Engine
}

\author{
Zhanhong Sun ${ }^{1, a}$, Yongsheng Huang ${ }^{2, b}$, Fengli $\mathrm{Li}^{3, \mathrm{c}}$ \\ ${ }^{1,2,3}$ changchun engineering technology college, Changchun, 130117, China \\ a2942440@qq.com, ${ }^{b} 256563540 @ q q . c o m,{ }^{7} 656886640 @ q q . c o m$
}

Keywords: Diesel Engine; Starting Trouble; Study

\begin{abstract}
Starting a diesel engine must have two conditions: one is the oil is enough, good atomizing diesel can arrive the combustion chamber. The second is to make the air temperature of the combustion chamber can improve to make the diesel oil fire. Its working process contains four steps of air suction, compression, acting and exhausting, during which starting trouble maybe appears occasionally .To improve its usability, efforts must be made to investigate the causes of and find out the solutions to the trouble.
\end{abstract}

\section{Introduction}

Diesel engine at room temperature, the general should start in 5 seconds. Sometimes requires repeated start 3 to 5 times also belongs to the normal, if after more than five times again and again start, diesel engine still cannot fire, should be regarded as start-up failure. This fault can cause many adverse consequences: such as motivation, performance, fuel consumption increase, etc. If there are mandatory start may damage the vehicle engine or other parts of the components. Diesel engines, therefore, once appear start difficult or unable to start, should be timely and careful analysis the reason, malfunction parts carefully, and take corresponding measures in time, troubleshooting, problem solving, resume the performance of the vehicle use.

\section{Fuel System Failures}

Diesel engine characteristics, composition and direction. The working characteristics of a diesel engine is: requirements on time, quality, volume, sending good atomization of fuel oil to diesel engine combustion chamber, the composition of the engine oil and fuel to as shown in figure 1 . The fuel tank - coarse filter - oil transfer pump - fine filter - fuel injection pump injector - extra fuel tank back.

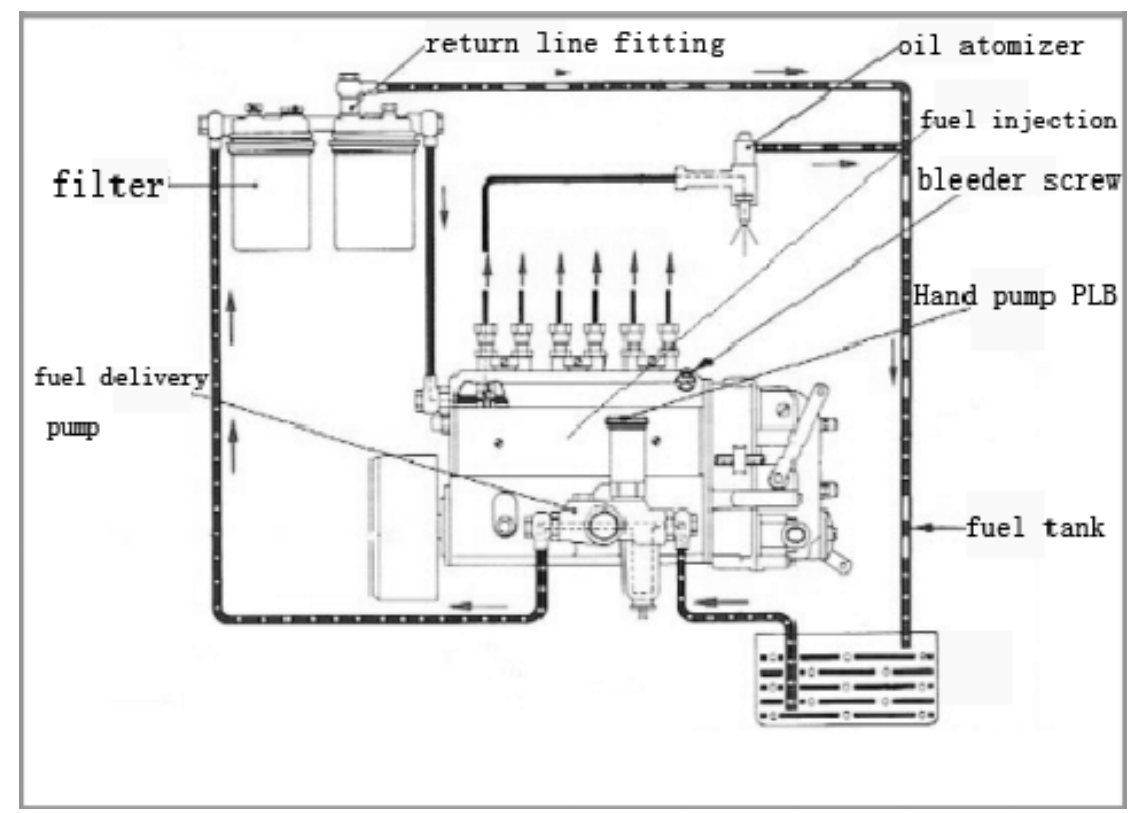

Fig.1 channel for oiling 
The fuel system fault analysis. Fuel supply system consists of tank, low pressure oil pipe, coarse filter, fine filter, fuel pump, fuel pumps, high pressure oil pipe and fuel injector, etc. Once any link between appear problem, can lead to abnormal oil supply. That cause diesel engine difficult to start or cannot start.

The faults of fuel system is the main cause of the engine does not start properly. So, make sure the fuel oil supply system works well, is to eliminate diesel engine start-up failure of the main measures. According to the composition of diesel engine fuel supply system structure analysis, resulting in abnormal oil factor mainly has the following several aspects: (1) in the fuel supply system in the air; (2) oil pipeline blocking phenomenon happened; (3) fuel filter blockage happened; (4) shortage of lubricating oil in oil pump damage caused; (5) fuel injection advance Angle adjustment improper; (6) Injection atomization effect is bad; All landowners injection pressure is too high or too low.

The fuel system fault solution. Through the analysis of the above factors, we can according to the principle of easy after the first difficult to gradually eliminate all kinds of problems. First of all, to check whether there is enough fuel tank of fuel, the fuel supply line whether there is loose phenomenon. If yes, then tighten the bolt connection part. Secondly, unscrew the deflated bolt assembly, clean air in the system.

If oil, should be cleaning pipe and filter. The final check for oil leakage, leakage oil transfer pump damage phenomenon. The above phenomenon is still can't start, after solving the recalibration fuel injection advance Angle, maintenance for fuel pump and fuel injector, readjust the injection pressure to solve the problem.

Application example. Have a tank truck, the engine USES is BF6M1015 diesel engine, the car after the secondary normal maintenance work, check the oil quality and oil plane, after normal replacement of diesel fuel filter, debugging vehicles, again and again to start the engine several times without any response.

First, check the car's fuel tank, found that the fuel tank is enough. Then remove the flowline joint on one side of the oil transfer pump. Observation, while with the hand pump oil found diesel strung out and no bubble, this phenomenon means that before the oil transfer pump oil is smooth and there is no air leakage, oil transfer pump work is intact.

Later, with tools unscrewed the vent screw on the diesel filter, the use of hand pumps to pump oil is shown in figure 2. Pump oil while observation, found that the position of the vent screw pump out the air bubble is contained in diesel oil, then this period of oil mixed with air, must clean the air out of the period of oil can make the vehicle normal operation. Then continue to pump oil with the hand pump, while the use of vent screw for air vent emptying, until clearly deflated screw position in oil pump out without air bubbles, means that the period of oil in the air already all discharge, oil flow, then start test, vehicle can start smoothly.

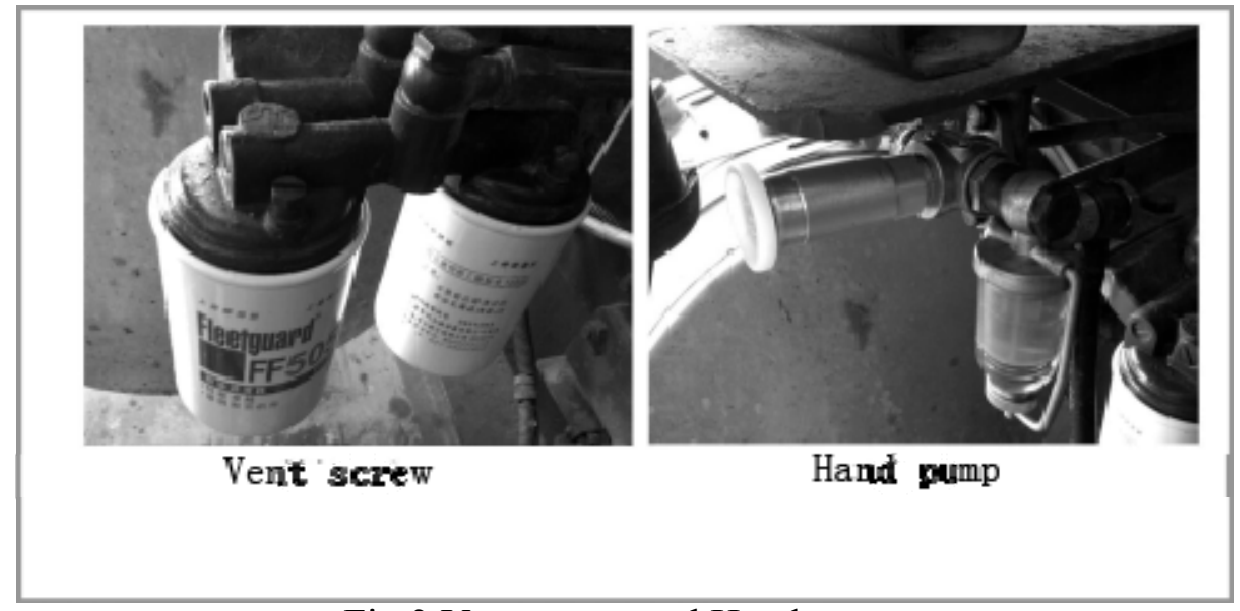

Fig.2 Vent screw and Hand pump

Can draw the following conclusion: diesel supply system with gas supply system, there is a difference between each time the discovery of oil is not clear or after changing some parts on the oil, and so on and so forth, relying only on simple pump oil pump does not work, also have to put this in the period of oil mixed with air discharge clean, to make the vehicle start smoothly. 


\section{Lubrication System Failure}

Lubricating oil. The role of the engine oil lubrication system is accurate, timely to the engine inside each operation of the surface of the parts supply a certain amount of lubricating oil, is used to reduce the friction resistance on the surface of the parts movement.

If the lubrication system of diesel engine working normal or not, can not be accurate, timely to the operation of the surface of the parts supply adequate lubricating oil, can cause parts motion resistance increase, make the motion to turn the difficult parts. What is more it is hard to start in diesel engine can be directly damage the diesel engine. So, a diesel engine lubrication system is working correctly, is directly related to the cause of the diesel engine can be normal boot.

Engine oil into the engine, is the main way of oil filling mouth filling into the engine oil pan, the oil pump to control the oil for lubrication. Then, through the oil filter, enter to the main vittae of the engine oil. Finally, branch let lubricating oil into all lubricating parts, such as fuel injection pump, crankshaft etc.

The oil lubrication problems and solutions. Oil lubrication is not good, the main cause of it is hard to start the engine has the following several aspects: (1) the oil viscosity on the high side; (2) oil deterioration of oil product; (3) engine oil is not enough, and so on and so forth.

The above several caused by oil in diesel engine by analyzing the reasons for not normal boot. First of all, we should check the vehicle cab engine oil pressure gauge on the dashboard, observations show that the oil pressure is belong to the normal range, if the oil pressure display is not normal, you should consider oil exists the phenomenon of poor lubrication, open out the oil feet observation. Check whether there is oil metamorphism too thin or viscosity too high, if this kind of situation, replace the heavy oil can be solved. Secondly, found the oil filter clogging or lack of oil, must want complement ensure adequate oil and engine oil and oil plug. Otherwise, this case to start the vehicle, it is very easy to cause the vehicle engine cylinder watts, led to the engine can't work normally even scrapped.

Application example. Existing a steam paraffin car, the engine USES is cummins diesel engine, the car on the road back to the yard one day, when the engine stalling. Is a novice driver because, want to restart the vehicle, engine startup of harsh "cut, cut, cut". For vehicle engine stop working after a period of time, will the car's engine oil feet out inspection, found the oil on the oil feet of scale is the lower limit position in oil feet, oil no bad phenomenon. As a result, our initial judgment is caused by lack of engine oil. Later, after completion of new filling oil, by the way, will vehicle check over other issues and to ensure that no any other conditions after the launch vehicle, the vehicle was successfully started.

Vehicles back to the field, after the inspection on the vehicle's engine oil feet every day, found to reduce the phenomenon of oil a day, after the car's engine to collapse, found in after the collapse of the engine oil burning phenomenon; Through the above situation we analysis the situation of the engine burning oil basically has the following several aspects: (1) the clearance between the piston and cylinder liner of engine is too large; (2) piston ring fracture occur; As long as the above situation, once happened, can make the oil through the splash form into the combustion chamber, causing the engine burning oil, leading to the oil.

\section{Starting System Failure}

Starting system failure reason and solution.Starting system failure is mainly starter power enough, work is normal, is good, these factors can directly affect the diesel engine start smoothly.

Through the analysis, start the main cause of the problem in the system are: (1) the generator does not work or bad work; (2) the vehicle circuit is poor contact phenomenon; (3)Battery power is insufficient; (4) starter does not work there is fault, etc.

To start the system fault solution. In view of the above reasons, we should first repair the vehicle each connecting wire is correct, and firm, is there a line of fracture phenomenon; Then by voltmeter check whether the power of the battery enough; Finally considering the generator is working correctly, the respect such as starter is working correctly. 
Application example.A certain kind of semi-trailer, a north toward the engine USES is BF6M1015 way according to the diesel engine, the car in a normal starting of the day, found the vehicle gap "well, well, well" sound, cannot drive diesel engine to work properly, vehicle can not start properly.

First of all, we examine the vehicle circuit, found no have poor contact or a fracture, whole vehicle power supply circuit is normal. Then connect the pile head remove, clean, remounted commissioning, still cannot solve the problem, fault is still there. Test whether the battery power is not enough, through the test of professional and technical personnel, battery voltage is enough. Disassembling inspection generator, also can prove that the generator can work properly, do not belong to the generator fault. Finally, we suspect is a starter failed to the normal vehicle can't start, we will BF6M1015 starter is removed, through debugging, prove that there is indeed a starter of failure. BF6M1015 starter and starter of the internal structure as shown in figure 3.

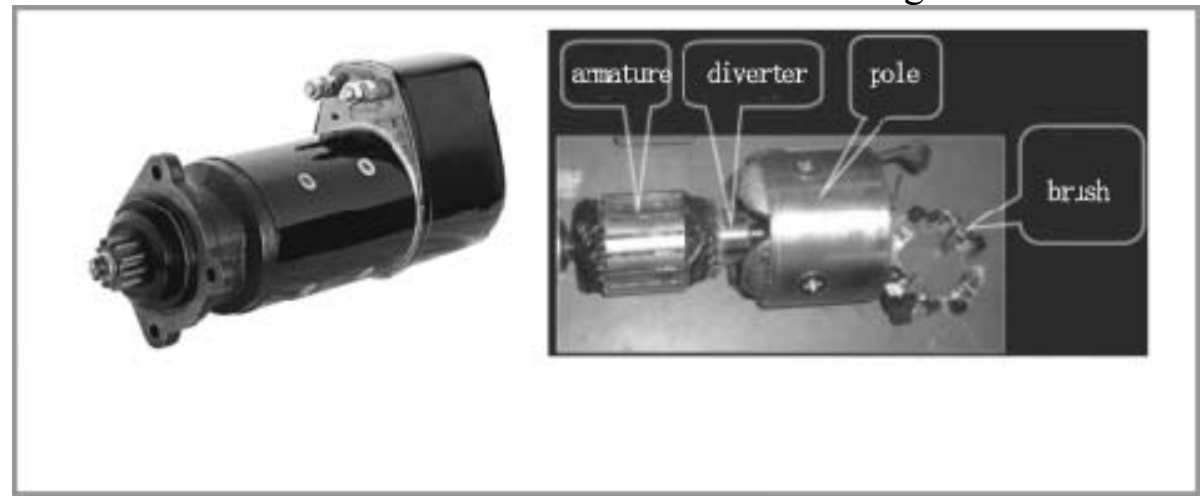

Fig.3 BF6M1015 Start the machine and internal structure

We suspect that the failure is due to the starter if there is a short circuit inside, excessive brush wear or a soft brush spring lead to problems such as. Disintegration check removal of starter and starter commutator is used gauze carefully polished clean, the surface is clean, and grinding starter brush face again, check the armature winding and commutator of the combination of parts; Found the problem at the site of the armature winding and commutator, the combining site of soldering appeared loose, lead to the starter resistance increases, leading to a starter overall power decrease, starter can't the normal starting, the fault occurred, the vehicle can't the normal starting; We will based on commutator and armature winding parts, welding with electric welding, after welding is firm is verified, the starter will reassemble, then start test, troubleshooting, starter motor vehicles normal boot.

\section{Conclusion}

Cause there are a number of diesel engine starting difficult. Diesel vehicles in the domestic car market also occupies a considerable proportion of, compared with gasoline vehicles, diesel vehicles in the use of existing in the process of fault, especially the part of the cause of the problem existing in the engine, with its unique diagnosis and maintenance methods. Therefore, we should according to different types of fault diagnosis from different parts of the engine repair, and extrapolate to master some common methods of fault diagnosis and maintenance methods of diesel engine, so as to improve the performance of diesel cars.

\section{References}

[1] Fengjiang Wei,Shuikang Han,Zuowei Dai.Diesel engine starting difficulty is analysed. automobile applying, 2010(09):47.

[2] Huaixin Yao,Engineering machinery engine theory and performance,China Communications Press, 2007.

[3] JL Hanson,Control for automatically starting a diesel engine,LL Howland - US Patent 4,878,465, 1989. 